\title{
Breakdowns' Diagnosis of A New Character Three-Phase High Voltage Power Supply for Industrial Microwave Generators with $\mathbf{N}=2$ Magnetrons per Phase
}

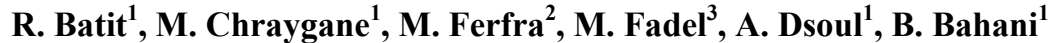 \\ ${ }^{1}$ Agadir High School of Technology, MSTI Research Team, Ibnou Zohr University, Agadir-Morocco \\ ${ }^{2}$ Mohammadia's School of Engineers, Research Team in Electrical Energy \& Control, \\ Mohamed V University, Rabat-Morocco \\ ${ }^{3}$ Laboratory of Electronic, Signal Processing and Physical Modeling, Ibn Zohr University, Agadir-Morocco
}

\begin{tabular}{l} 
Article Info \\
\hline Article history: \\
Received Oct 12, 2015 \\
Revised Jan 5, 2016 \\
Accepted Jan 20, 2016 \\
\hline
\end{tabular}

\section{Keyword:}

Breakdowns' diagnosis Magnetron

EMTP

Modelling

Regulation

\begin{abstract}
This paper treats the modelisation of a new three phase character high voltage supply (HV) for industrial microwave generators with $\mathrm{N}=2$ magnetrons per phase. This alimentation is based on the presentation of an equivalent $\pi$ circuit model of a newly dimensioned high voltage transformer. Each phase of the three phase system supplies two parallel cell voltage doublers and current stabilizer. Each of these cells in turn supplies one magnetron 800 Watts $/ 2.45 \mathrm{GHz}$. This power supply is a star connection of three identical models of the single-phase power for $\mathrm{N}=2$ magnetrons. The simulation under EMTP (Electro Magnetic Transients Program) in nominal conditions allows concluding that theoretical results are adjacent to the experimental measurements. Furthermore, a failure study of six magnetron of the microwave generator is also processed. The results permit to observe that the interaction between magnetrons dosn't influence the nominal operation of the system.
\end{abstract}

Copyright (C) 2016 Institute of Advanced Engineering and Science. All rights reserved.

\section{Corresponding Author:}

Redouane BATIT,

Research Team of Modelisation, Systems and Information of Technology,

Ibnou Zohr University,

High School of Technology, BP: 33/S 80000, Agadir-Morocco.

Email: redouane.batit@edu.uiz.ac.ma

\section{INTRODUCTION}

The Figure $1 \mathrm{~A}$ indicates a microwave power supply for industrial application requiring 4800 Watts of power for $\mathrm{N}=6$ magnetrons (each magnetron needs a power of 800 Watts to generate a high frequency wave of $2.4 \mathrm{GHz}$ ). These magnetrons are powered by 6 ordinary transformers with magnetic shunt, through six cell voltage doublers. In Figure 1B, the configuration of this microwave supply system is improved by reducing the number of transformers to 3 transformers, newly dimensioned, each of which is capable of supplying the power of two magnetrons simultaneously. Last but not least a new three phase microwave power supply is developed in order to be able to provide the useful power required for the 6 magnetrons. This new power supply is more optimal in terms of its mass and its volume; also it reduced the wiring congestion, which reduces the costs of manufacturing and maintenance.

Figure 2 shows the schematic diagram of the new three-phase character high voltage power supply for $\mathrm{N}=2$ magnetrons. It is a star connection of three high voltage leakage field transformers that each one supplies two doublers cells voltage and current stabilizers. 


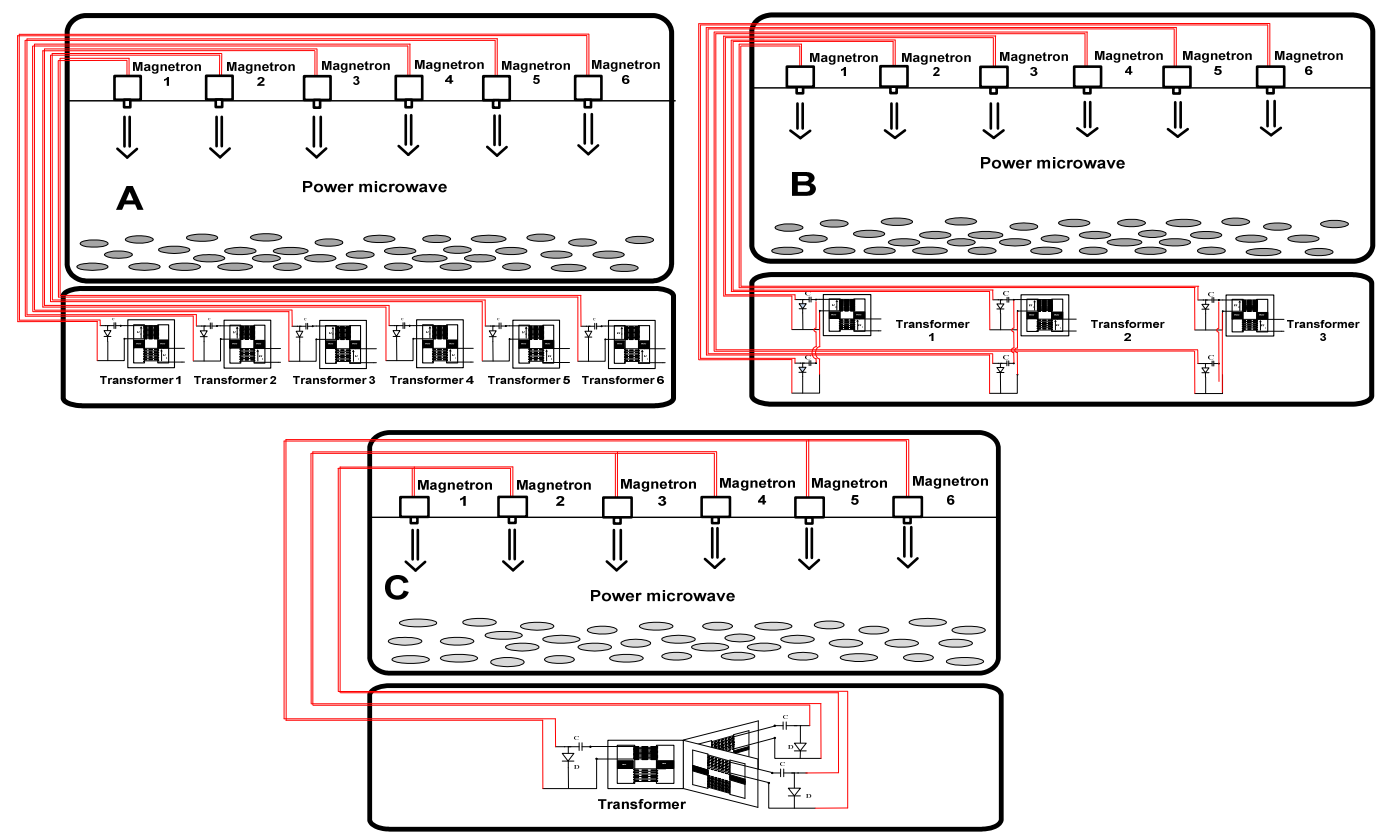

Figure1. (A) Classical single phase microwave power supply for $\mathrm{N}=6$ magnetrons (B) The new single phase microwave power supply for $\mathrm{N}=6$ magnetrons

(C) The new three phase microwave power supply for $\mathrm{N}=6$ magnetrons

This article consists of two main parts: In the first part, we present an equivalent circuit diagram of the new character three-phase high voltage power supply constituted of three identical models star-connected of single-phase high voltage power supply for $\mathrm{N}=2$ magnetrons [1]-[3]. The simulation of the new threephase high voltage power supply electrical operation allowed to observe its different time dependent curves of different currents and voltages.And that to compare with those obtained experimentally [4]-[6] in conventional single-phase high voltage power supply for single magnetron (Figure 6.B). Finally, the anode current regulation process in each magnetron has been completely verified.

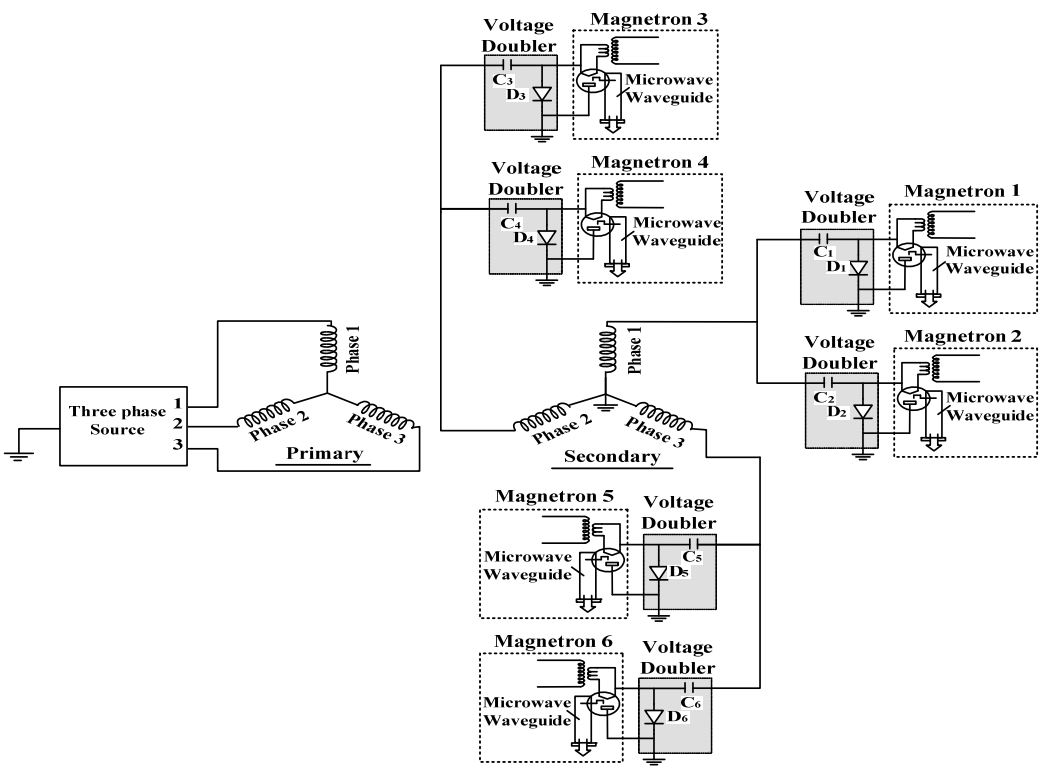

Figure 2. Character three phase high voltage power supply for two magnetrons per phase

Concerning this new character three-phase high voltage power supply for two magnetrons per phase, the second part of this article was devoted to studying the influence of one or more magnetrons failures on 
the electric operation of the rest of the other functional magnetrons. In this failure's study; we will successively analyze the following cases:

- One faulty magnetron and five magnetrons in service.

- Two faulty magnetrons and four magnetrons in service.

- Three faulty magnetrons and three magnetrons in service.

- Four faulty magnetrons and two magnetrons in service.

- Five faulty magnetrons and one magnetron in service.

- Six faulty magnetrons.

\section{PROPOSED METHOD FOR THE MODELING OF THE NEW THREE PHASE HIGH}

VOLTAGE POWER SUPPLY FOR TWO MAGNETRONS PER PHASE

The equivalent circuit diagram should reflect the behavior of the entire power supply circuit including the magnetron and the transformer with magnetic shunt. On the one hand the solving of the electric and magnetic equations of the whole system is too complicated, and the solution could be only numeric using the EMTP simulation software, with the possibility of studying the selection of materials and dimensions of the transformer for further optimization. On the other hand the EMTP software [7]-[9] takes into account the nonlinearities of the system, by accepting the data relating to the saturable inductors.

The advantage of the second model of quadrupole in $\pi[10]-[12]$ is in its single phase equivalent circuit which would be more convenient for studying the transformer's functioning with EMTP. This model is natural, because each iron core inductor is a function of its reluctance, so it's a function of the permeability of a specific part in the magnetic circuit, that is assumed fictively closed on which are wound $\mathrm{n}_{2}$ secondary turns. The immediate benefit of this model, is being able to assign to each inductor a nonlinear relationship "current-flow" in the form of $\mathrm{n} 2 \Phi(\mathrm{i})$, from the geometrical parameters of a specific portion of the transformer's magnetic circuit, which allows to interpret its reel operation in nonlinear regime.

There is another equivalent electrical model of the transformer with magnetic shunt, named the model in T [13],[14], but it doesn't reflect the nonlinearity of the inductors, associated to each portion of the transformer.

\subsection{Single-phase high voltage power supply for two magnetrons: Equivalent circuit model}

The transformer in Figure 3 is considered without iron losses due to hysteresis and Foucault currents; only the saturation phenomenon is taken into account. The functioning of the transformer is characterized by the following system of magnetic and electric equations:

$$
\begin{aligned}
& v_{1}=r_{1} 1_{1}+r_{1}, d \oplus_{1} / d t \\
& \mathrm{~V}_{2}=-v_{2} I_{2}+n_{2} d \omega_{2} / d t \\
& \mathbb{R}_{\mathrm{P}} \boldsymbol{\phi}_{1}+\mathbb{R}_{\mathrm{sh}} \boldsymbol{\phi}_{\mathrm{g}}=\mathrm{n}_{\mathrm{L}} \mathbb{1}_{\mathrm{l}} \\
& \mathbb{R}_{2} \vartheta_{2}-\mathbb{R}_{\mathrm{sh}} \varphi_{4}=-n_{2} \|_{2} \\
& \theta_{1}=\varphi_{2}+\varphi_{1}
\end{aligned}
$$

After the transformation of the five above equations (1) to (5), we obtain the six following equations (6) to (10), which reflect the equivalent electric model in $\pi$ of the transformer with magnetic shunt.

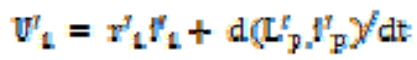

$$
\begin{aligned}
& \mathrm{V}_{2}=-v_{2} \mathrm{I}_{2}+\mathrm{d}\left(\mathrm{L}_{\mathrm{s}} \mathrm{i}_{\mathrm{g}}\right) / \mathrm{dt}
\end{aligned}
$$

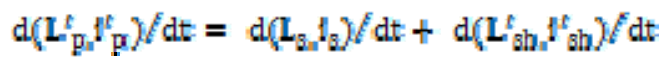

$$
\begin{aligned}
& f_{1}^{f}=f_{\mathrm{P}}^{\mathrm{f}}+1_{\mathrm{sh}}^{\mathrm{k}} \\
& i_{\text {sh }}^{t}=I_{2}+I_{\Sigma}
\end{aligned}
$$




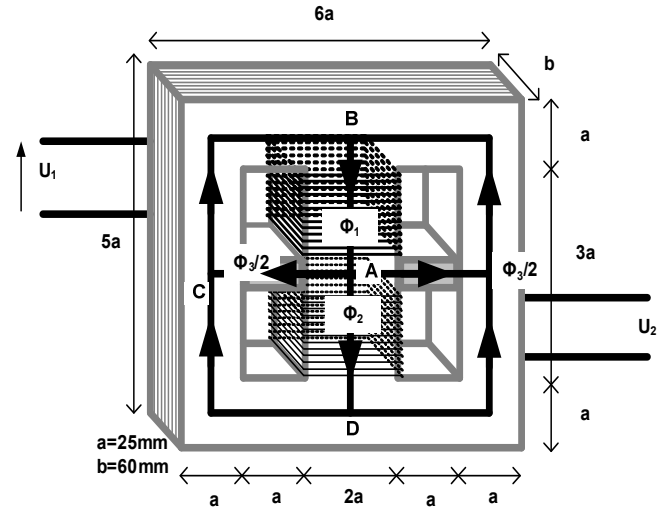

$\mathrm{n}_{1}$ : primary coil's turns

$\mathrm{n}_{2}$ : secondary coil's turns

$\mathrm{U}_{1}$ : primary voltage

$\mathrm{U}_{2}$ : secondary voltage

$r_{1}$ : resistance in the primary windings

$r_{2}$ : resistance in the primary windings

$i_{1}$ : primary current

$\mathrm{i}_{2}:$ secondary current

$i_{p}^{\prime}, R_{p}, L_{p}^{\prime}$ : current, reluctance and inductance associated with de party $[A B C]$

i'sh, $R_{\text {sh }}, L_{\text {sh }}$ : current, reluctance and inductance associated with de party $[A C]$

$i_{s}, R_{s}, L_{s}$ : current, reluctance and inductance associated with de party [ADC]

Figure 3. Geometrical characteristics of magnetic and electric circuit of the transformer with magnetic shunt

The figure 4 shows the scheme $\pi$ of this power supply. We note that each of the three saturable inductors is a function of its own reluctance [15],[16], so it's also a function of its own permeability in a précised part of the correspondente magnetic circuit, which is supposed fictitiously closed, and in which $\mathrm{n}_{2}$ secondaries turs are rolled. This model was successfully verified [17]-[19] and showed that each magnetron delivers its full desired power.

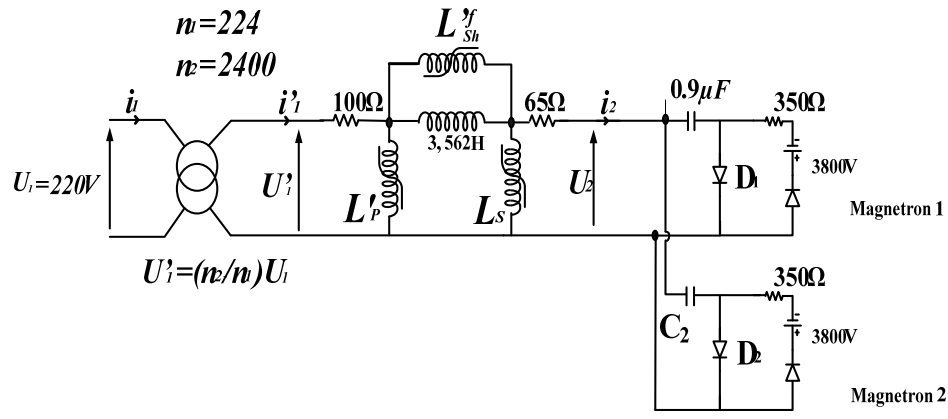

Figure 4. Electrical equivalent model of the single phase high voltage power supply for two magnetrons

\subsection{New three-phase high voltage power supply for two magnetrons per phase}

To achieve the new three-phase system in the two Figures 2 and 5, we have just to star couple three models (identical to that described in Figure 3 that will be supplied respectively by single-phase voltages with a phase difference of 120 degrees. It should be recalled that each model of the secondary side comprises a high voltage transformer with appropriate sized shunts which drives two identical loads in parallel that are composed by a voltage doubler (capacitor and diode) and magnetron.

\section{RESULTS AND DISCUSSION}

The simulation under EMTP of the electrical operation of the three-phase character HV power supply for $\mathrm{N}=2$ magnetrons per phase was performed for each case of breakdown. The observation of the obtained waveforms from the currents and voltages allowed making the corresponding analysis of the different characteristics of its high voltage circuit and particularly that of the magnetron current.

\subsection{The simulation in EMTP of the equivalent circuit model of the new character three-phase high voltage power supply}

The electrical operation of the new three-phase power supply described in Figure 5 of microwave generator with six magnetrons in total (two magnetrons per phase) was simulated in EMTP, which allowed us to obtain the time curves (Figure 6.a) of voltages (Condenser, diode and magnetron) and currents (diode, magnetron and secondary). The three primaries nominals voltages of the studied power supply have the same rms $220 \mathrm{~V}-50 \mathrm{~Hz}$ and are phase shifted 120 degrees. 


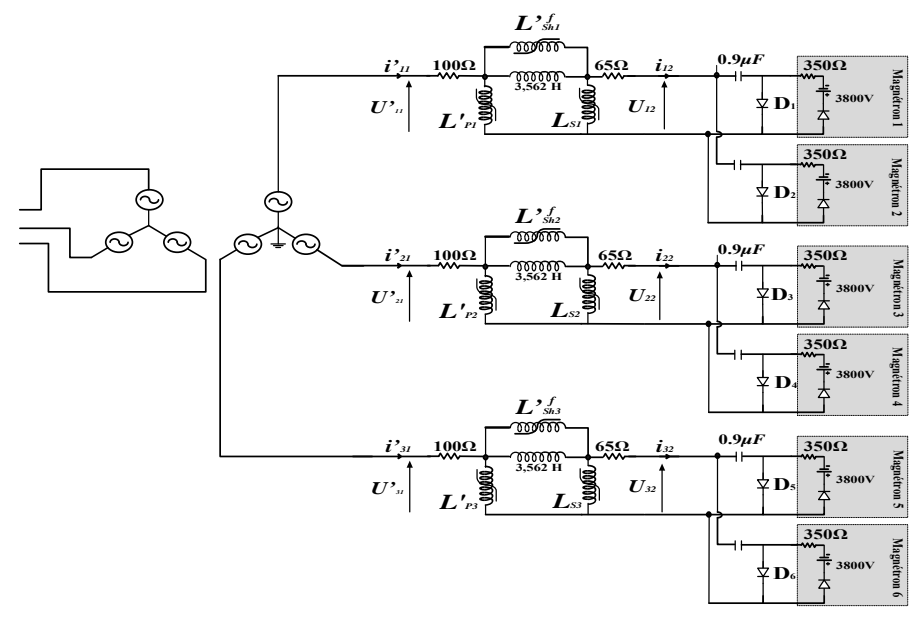

Figure 5. Character three phase high voltage power supply for two magnetrons per phase (Equivalent circuit model)
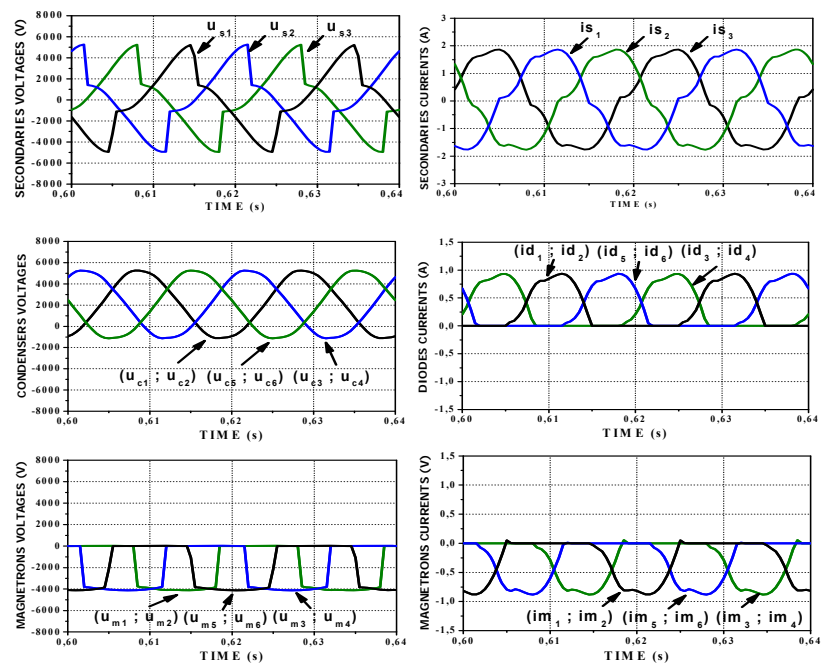

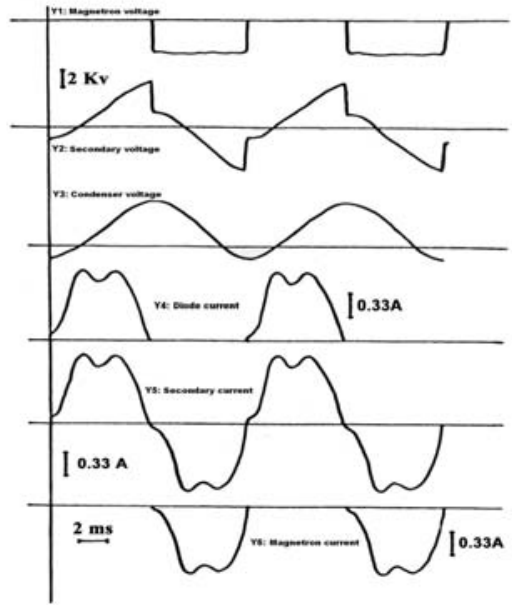

b.

Figure 6. Simulation and experimental results, a). The simulation's results with EMTP of a character three phase high voltage power supply for two magnetrons per phase, $b$ ). The experimental waveforms of currents and voltages of a single phase high voltage power supply for one magnetron (nominal mode)

For each of the two magnetrons of same phase in nominal operation $(220 \mathrm{~V}$ and $50 \mathrm{~Hz}$ in primary side), the electric current's signals (diode, magnetron and secondary side) and voltages (capacitor, magnetron and secondary side) may constitute an assembly which have the same form as that of single magnetron's conventional feeding. These signals are periodic variable quantities (but they are not sinusoidal), globally for all three phases simultaneously feeding two magnetrons, therefore there are three successive sets of signals which are phase shifted by 120 degrees. It can be concluded that the curves obtained through simulation in EMTP of new simultaneous power supply's three-phase device of two magnetrons per phase (in non-linear regime), are in accordance with the experimental waveforms recorded in the case of single magnetron's single-phase power supply (Figure 6.b).

We observe that the maximum value of current magnitude in each of both identical magnetrons in each of three phases remains less than the limit $(<1,2 \mathrm{~A})$, which respects the constraints imposed and recommended by the manufacturer of magnetrons thus ensuring the correct operation of the microwave tube. Taking into account the foregoing, the informations mentioned before, the electrical current stabilization process in each magnetron is completely verified, as shown in Figure 7. 

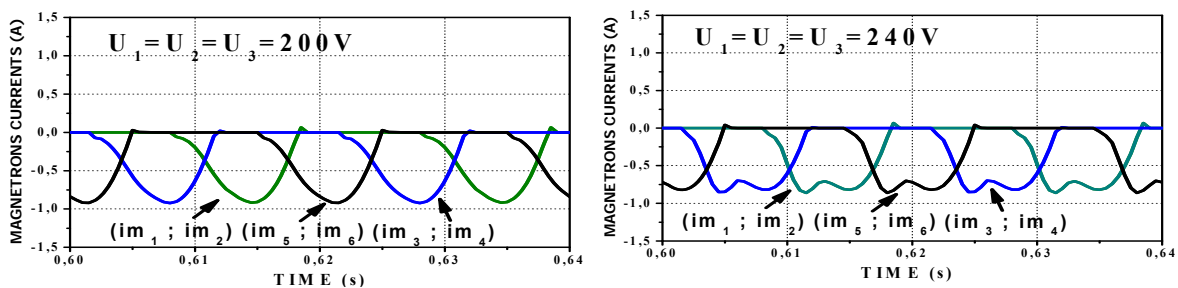

Figure 7. Stabilization of the anode current of the magnetron in relation with variations in the mains voltage $+10 \%$ of the nominal voltage

\subsection{Case of one faulty magnetron and five magnetrons in service}

The simulation results under EMTP code of the assembly of Figure 8.a are indicated in Figure 8B. We observe that the magnetron breakdown of phase 1 reduces the operation of the corresponding voltage doublers which supplies it, composed of one diode $\mathrm{D}_{1}$ and one condenser $\mathrm{C}_{1}$ having $0.9 \mu \mathrm{F}$. The latter has to be charged through the diode $\mathrm{D}_{1}$ at the secondary peak voltage delivered by the high voltage transformer.

The operating point of each running magnetron is not disturbed. The breakdown of one between six powered magnetrons does not change the operation of the five remaining magnetrons in service. For the phase containing two magnetrons, a magnetron in breakdown and a running magnetron, we observe at the commutation time of the diode the presence of transient oscillations, at the level of the voltages across the functional magnetron and the secondary of the transformer (Figure 8.b). This is simply due to the change of the nominal operating point of the magnetron running of this phase. Each of the two other phases containing two running magnetrons, the absence of transient oscillations at the level of voltages indicates the correct electrical operation of these two magnetrons.

For the phase containing two magnetrons, a magnetron in breakdown and a running magnetron, we observe at the commutation time of the diode the presence of transient oscillations, at the level of the voltages across the functional magnetron and the secondary of the transformer (Figure 8.b). This is simply due to the change of the nominal operating point of the magnetron running of this phase. Each of the two other phases containing two running magnetrons, the absence of transient oscillations at the level of voltages indicates the correct electrical operation of these two magnetrons.

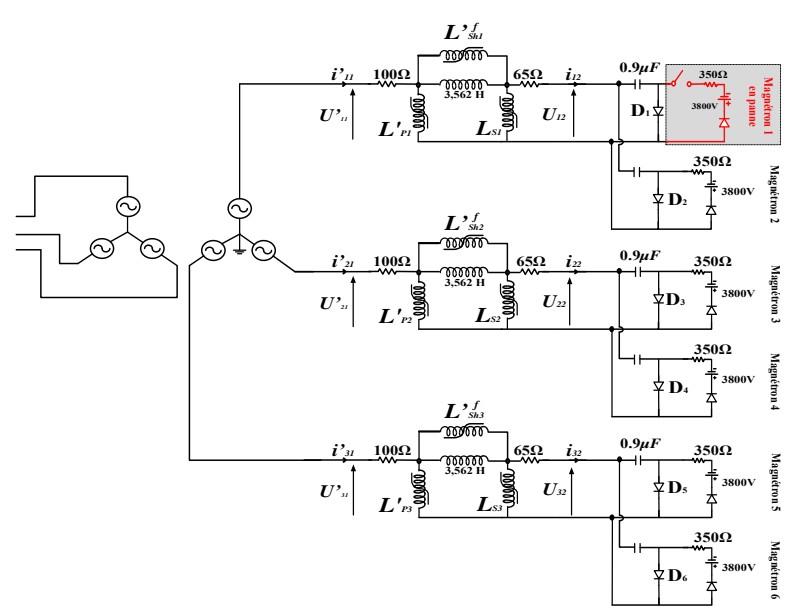

a.
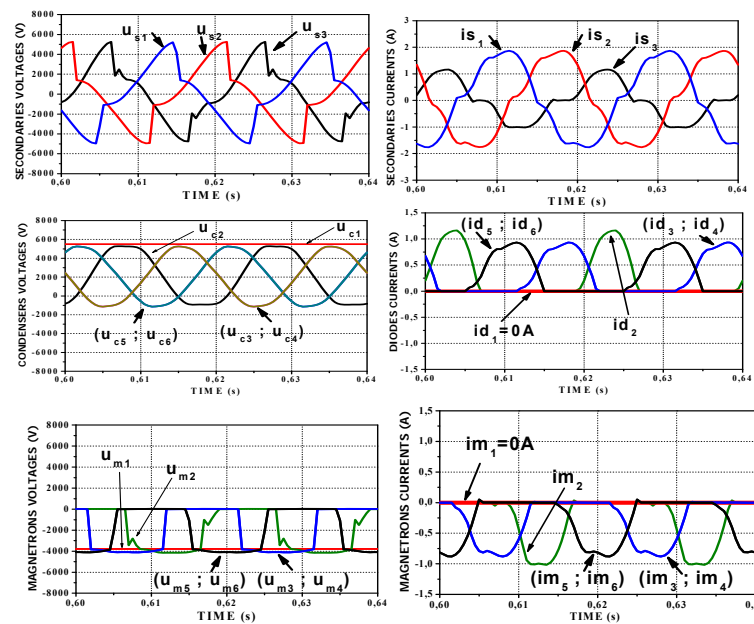

b.

Figure 8. Circuit Models: case of one faulty magnetron and five magnetrons in service a). Circuit model of a character three phase $\mathrm{HV}$ power supply for $\mathrm{N}=2$ magnetrons per phase, $\mathrm{b}$ ). Waveforms of currents and voltages of the circuit in Figure 8.a.

\subsection{Case of two faulty magnetrons and four magnetrons in service}

\subsubsection{Case of two faulty magnetrons in the same phase}

The simulation's results with EMTP code of the assembly in Figure 9.a are shown in Figure 9.b. It is noted that each of the two faulty magnetrons of same phase 1 reduces the operation of its corresponding voltage doubler, consisting of one diode and one condenser having $0.9 \mu \mathrm{F}$. This condenser has to charge through the diode D1 at the secondary peak voltage supplied by the high voltage transformer. 
For each of the other two phases, the operating point of each of the two magnetrons in service is not disrupted. The failure of both magnetrons of the same phase doesn't affect the operation of the remaining four magnetrons in service of the other two phases. The two faulty magnetrons of same phase (phase 1) have no interaction effect on the operation of the four other functional magnetrons (phase 2 and phase 3 ). Given that their operating points are not disturbed.

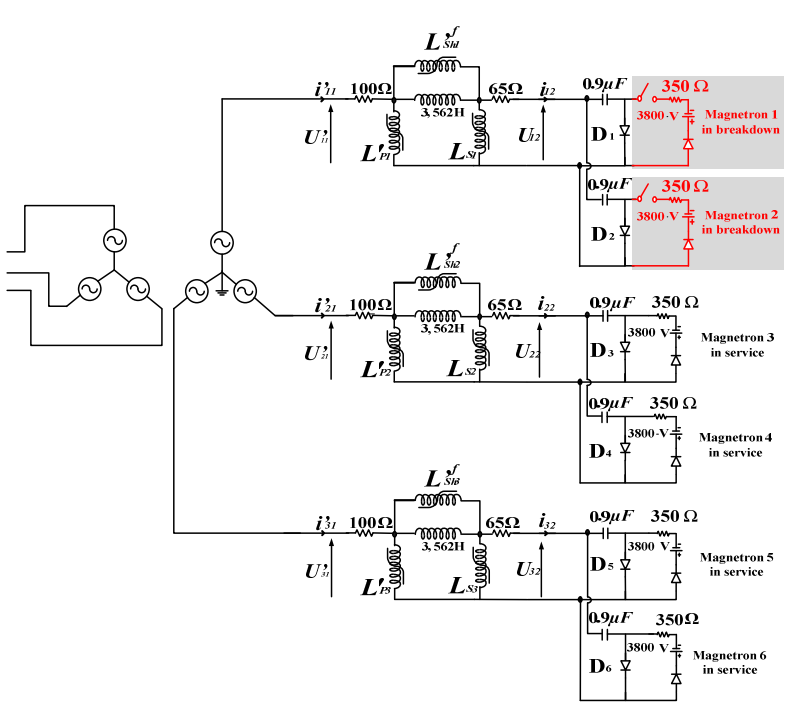

a.
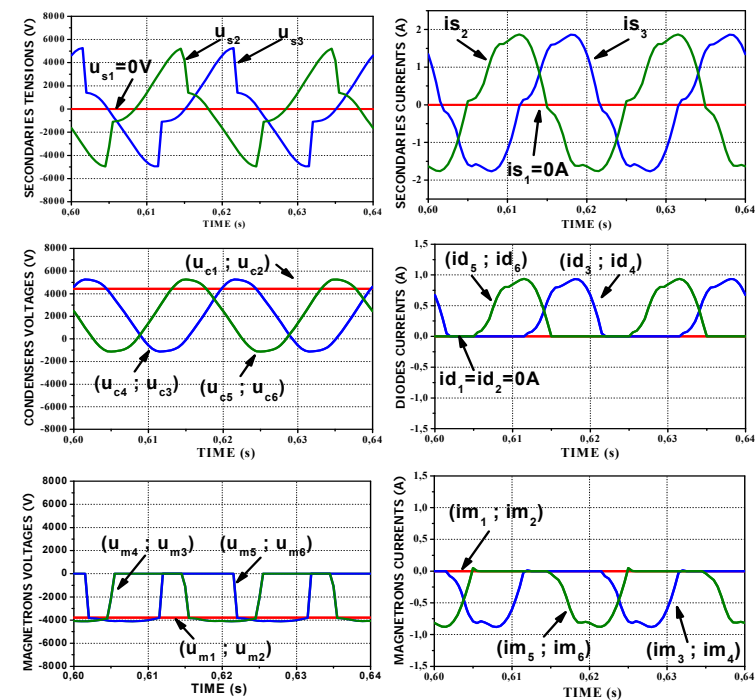

b.

Figure 9. Circuit model: Case of two faulty magnetrons in the same phase, a). Circuit model of a character three phase HV power supply for $\mathrm{N}=2$ magnetrons per phase, $\mathrm{b}$ ). Waveforms of currents and voltages of the circuit in Figure 9.a.

\subsubsection{Case of two faulty magnetrons that each one is placed in different phase}

The simulation's results with EMTP of the assembly in Figure 10.a are shown in Figure 10.b.

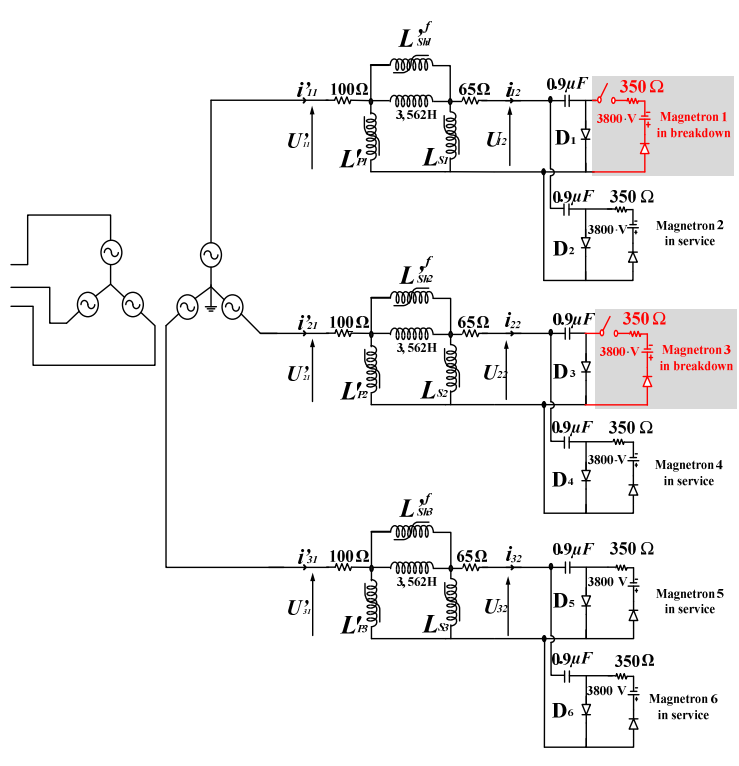

a.
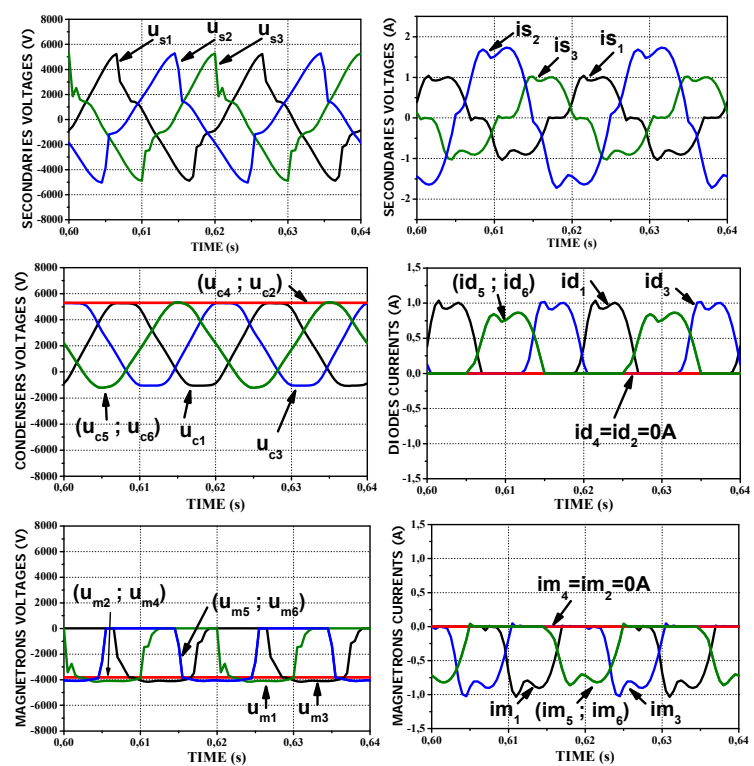

Figure 10. Circuit models : Case of two faulty magnetrons that each one is placed in different phase, a). Circuit model of a character three phase HV power supply for $\mathrm{N}=2$ magnetrons per phase, $\mathrm{b}$ ). Waveforms of currents and voltages of the circuit in Figure 10.a. 
It is noted that one faulty magnetron of phase 1 reduces the operation of its corresponding voltage doubler, consisting of diode D1 and condenser $\mathrm{C} 1$ having $0.9 \mu \mathrm{F}$. This capacitor has to charge through the diode D1 with the secondary peak voltage supplied by the high voltage transformer. The operating point of the functional magnetron of same phase is not disturbed. In the same way, the faulty magnetron of the phase 2 reduces the operation of its corresponding voltage doubler, consisting of one diode $\mathrm{D}_{3}$ and one condenser $\mathrm{C}_{3}$ having $0.9 \mu \mathrm{F}$. This condenser has to charge through the diode $\mathrm{D}_{3}$ with the secondary peak voltage supplied by transformer. The operating point of the functional magnetron of this phase is not disturbed. For each one of the three phases which contains two magnetrons: one faulty magnetron and one magnetron in service, we observe in the diode switching time, the presence of transient oscillations at the level of the voltages across the functional magnetron and the transformer's secondary (Figure 10.b). This is simply due to the change of the nominal operating point of the functional magnetron in this phase.

For one of the three phases which contains two functional magnetrons, the absence of transient oscillations at the voltages indicates that the electrical operation of two magnetrons is perfectly nominal. At the level of this phase, the waveform's temporal characteristic obtained from the secondary current presents, in every instant, double amplitude than that of the same current in the case of two faulty magnetrons that each one is placed in different phase. This is due to the fact that these two magnetrons debit their full power simultaneously in a proper manner. From the study of the two cases, we conclude that the failure of two of the six powered magnetrons doesn't change the operation of the other four magnetrons in service.

\subsection{Case of three faulty magnetrons and three magnetrons in service}

\subsubsection{Case of Three faulty magnetrons which everyone is in each phase}

On the one hand, the simulation's results through EMTP of the assembly in Figure 11.a are shown in Figure 10.b. It is noted that each faulty magnetrons (in one of the three phases) reduces the functioning of its corresponding voltage doubler, consisting of one diode and one condenser having $0.9 \mu \mathrm{F}$. This condenser has to charge through the diode $\mathrm{D}_{1}$ at the secondary peak voltage supplied by the high voltage transformer.

On the other hand, we observe in the diode switching time the presence of transient oscillations at the level of the voltages across the functional magnetron and the transformer's secondary (Figure 11.b). This is simply due to the change of the nominal operating point of the functional magnetron. The failure of this magnetron doesn't disturb the functioning of the other magnetrons in service. The three faulty magnetrons have no interaction effect on the functioning of the three other functional magnetrons. Given that their operating points are not disturbed.

\subsubsection{Case of Three faulty magnetrons which two are in the same phase}

The simulation's results with EMTP of the assembly in Figure 12.a are shown in Figure 12.b. It is noted that each of the two faulty magnetrons of same phase reduces the operation of its corresponding voltage doubler, consisting of one diode and one condenser having $0.9 \mu \mathrm{F}$.

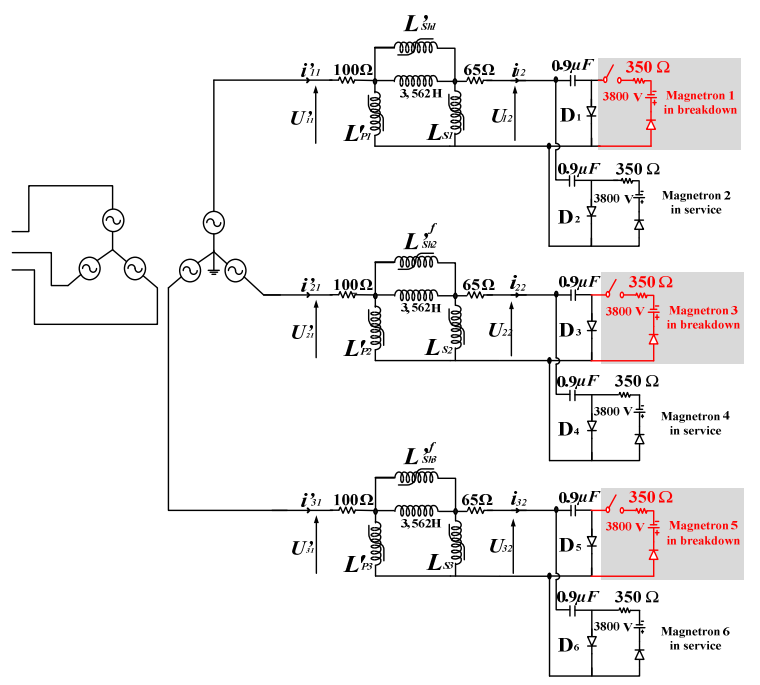

a.
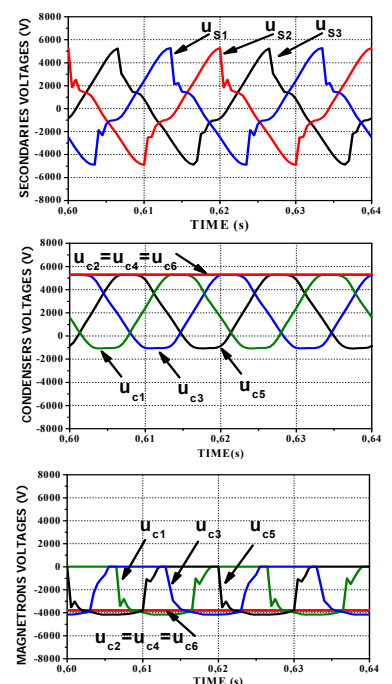

b.
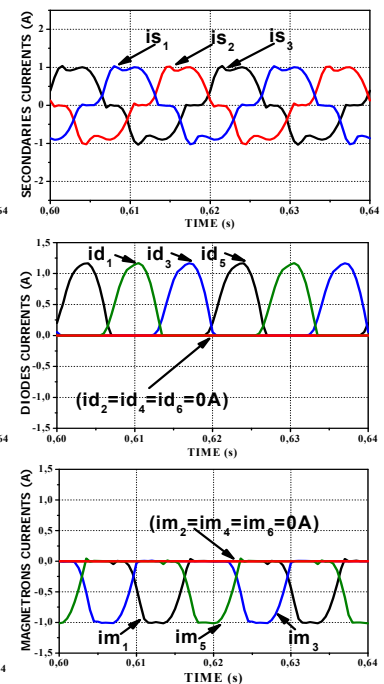

Figure 12. Circuit model: Case of Three faulty magnetrons in each phase, a). Circuit model of a character three phase HV power supply for $\mathrm{N}=2$ magnetrons per phase, $\mathrm{b}$ ). Waveforms of currents and voltages of the circuit in Figure 11.a. 
This condenser has to charge through the diode $\mathrm{D}_{1}$ at the secondary peak voltage supplied by the high voltage transformer. The failure of these magnetrons doesn't disturb the functioning of the other magnetrons in service.

Concerning the phase which contains two magnetrons: one faulty magnetron and one magnetron in service, we observe in the diode switching time, the presence of transient oscillations at the level of the voltages across the functional magnetron and the transformer's secondary (Figure 12.b). This is simply due to the change of the nominal operating point of the functional magnetron. The failure of this magnetron doesn't disturb the functioning of the other magnetrons in service. The three faulty magnetrons have no interaction effect on the functioning of the three other functional magnetrons. Given that their operating points are not disturbed.

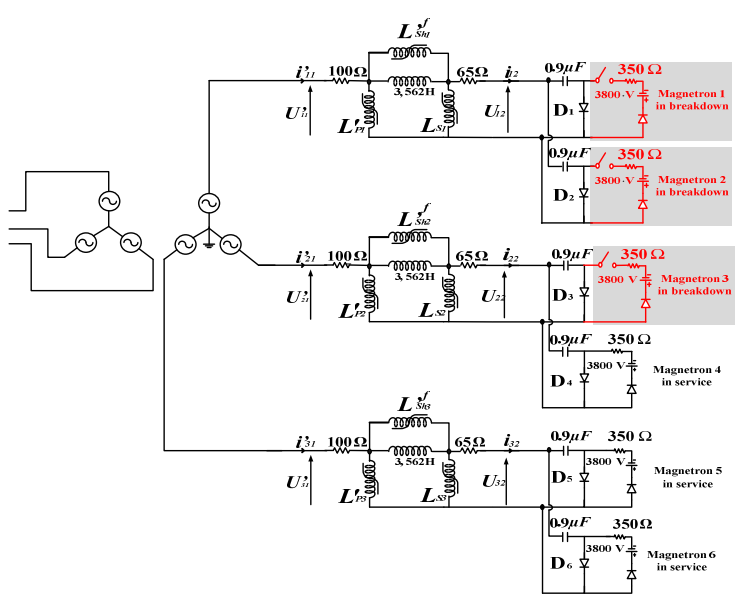

a.
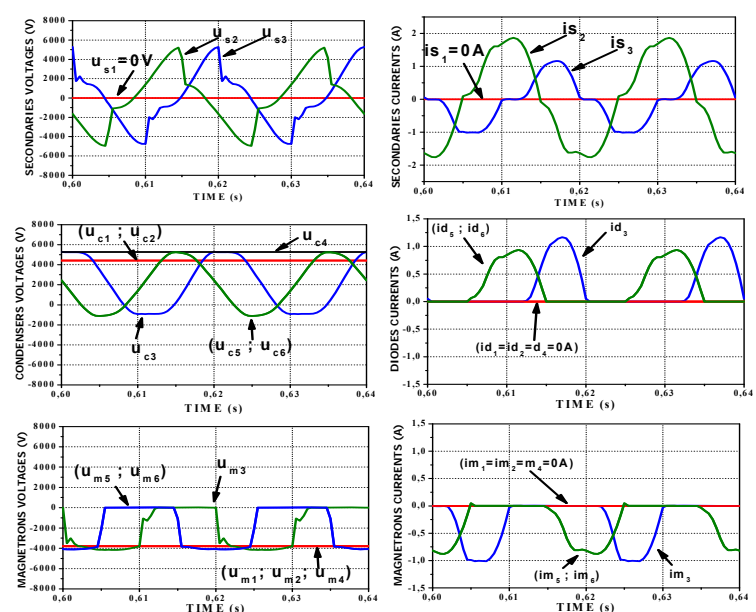

b.

Figure 12. Circuit model: Case of Three faulty magnetrons which two are in the same phase, a). Circuit model of a character three phase HV power supply for $\mathrm{N}=2$ magnetrons per phase, $b$ ). Waveforms of currents and voltages of the circuit in Figure 12.a

3.5. Case of four faulty magnetrons and two magnetrons in service

3.5.1. Case of Two faulty magnetrons in the two of the three phases (phase1 and phase2)

The simulation's results through EMTP of the assembly in Figure 13.a are shown in Figure 13.b.

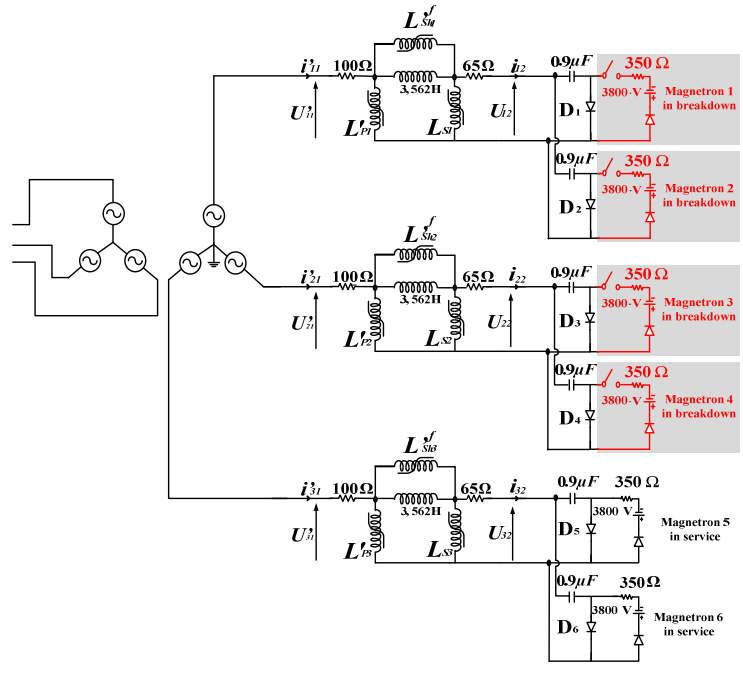

a.
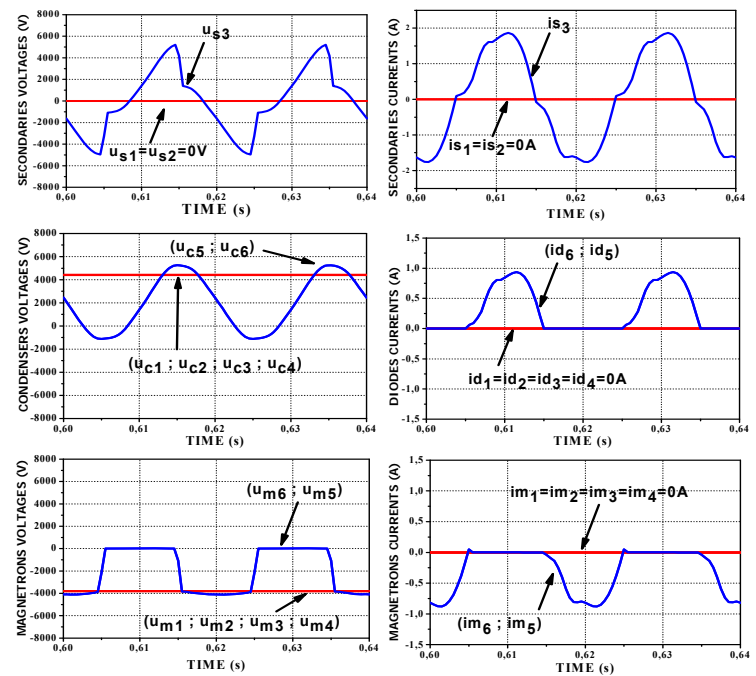

b.

Figure 13. Circuit model: Case of Two faulty magnetrons in one phase (phase 1 or phase 2), a). Circuit model of a character three phase $\mathrm{HV}$ power supply for $\mathrm{N}=2$ magnetrons per phase, $\mathrm{b}$ ). Waveforms of currents and voltages of the circuit in Figure 13.a. 
It is noted that each of the two faulty magnetrons (in one among the two phases 1 and 2) reduces the functioning of its corresponding voltage doubler, consisting of one diode and one condenser having $0.9 \mu \mathrm{F}$. This condenser has to charge through the diode at the secondary peak voltage supplied by the high voltage transformer. Each faulty magnetron doesn't disturb the functioning of the other magnetrons in service.

The two faulty magnetrons of same phase (phase 1 and phase 2) have no interaction effect on the functioning of the two other functional magnetrons (of phase 3). Given that their operating points are not disturbed.

\subsubsection{Case of Two faulty magnetrons in one phase and one faulty magnetron in each of the other two phases}

The simulation's results through EMTP of the assembly in Figure 14.a are shown in Figure 14.b. It is noted that each of the two faulty magnetrons of same phase (phase 1) reduces the functioning of its corresponding voltage doubler, consisting of one diode and one condenser having $0.9 \mu \mathrm{F}$. This condenser has to charge through the diode at the secondary peak voltage supplied by the high voltage transformer. The failure of these two magnetrons doesn't disturb the functioning of the other magnetrons in service.

For each one of two other phases ( phase 2 and phase 3) which contains two magnetrons: one faulty magnetron and one magnetron in service, we observe in the diode switching time, the presence of transient oscillations at the level of the voltages across the functional magnetron and the transformer's secondary (Figure 14.b). This is simply due to the change of the nominal operating point of the functional magnetron in this phase. The failure of one magnetron in each phase does not disturb the functioning of the other magnetrons in service. The four faulty magnetrons have no interaction effect on the functioning of the other two functional magnetrons, given that their operating points are not disturbed.

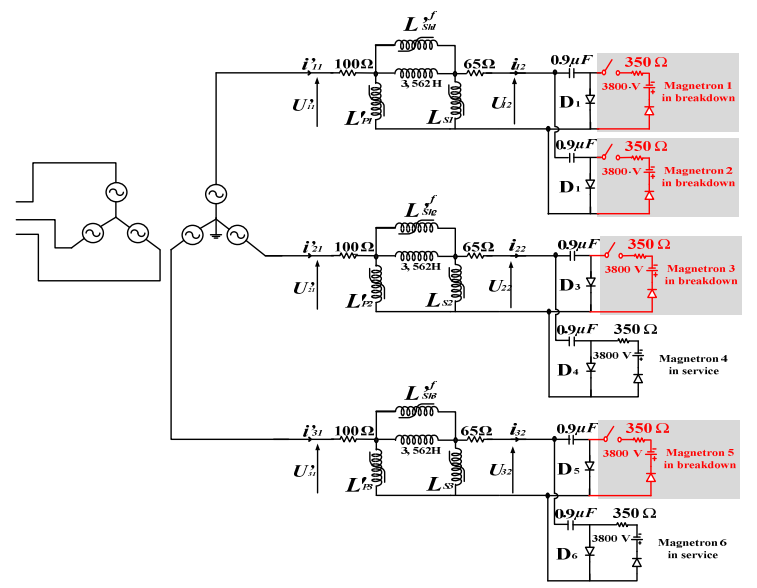

a.
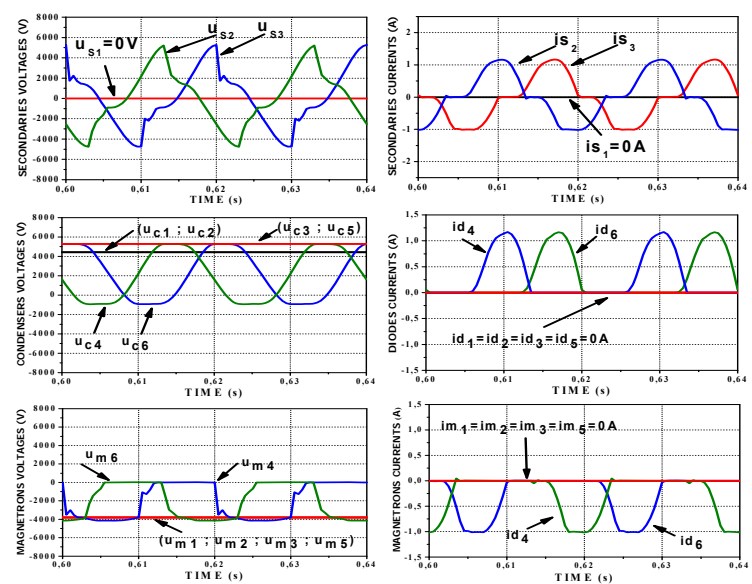

Figure 14. Circuit Model: Case of Two faulty magnetrons in one phase and one faulty magnetron in each of the other two phases, a). Three phase HV power supply for $\mathrm{N}=2$ magnetrons per phase, b). Waveforms of currents and voltages of the circuit in Figure 14.a

\subsection{Case of five faulty magnetrons and one magnetron in service}

The simulation's results through EMTP of the assembly in Figure 15.a are shown in Figure 15.b. It is noted that each of the two faulty magnetrons (in one among the two phases 1 and 2) reduces the functioning of its corresponding voltage doubler, consisting of one diode and one condenser having $0.9 \mu \mathrm{F}$. This condenser has to charge through the diode at the secondary peak voltage supplied by the high voltage transformer. The failure of these two magnetrons doesn't disturb the functioning of the other magnetrons in service.

Concerning the other remaining phase (phase 3) which contains two magnetrons: one faulty magnetron and one magnetron in service, we observe in the diode switching time, the presence of transient oscillations at the level of the voltages across the functional magnetron and the transformer's secondary (Figure 15.b). This is simply due to the change of the nominal operating point of the functional magnetron in this phase. The failure of one magnetron in this phase does not disturb the functioning of the other magnetrons in service. The five faulty magnetrons have no interaction effect on the functioning of the other magnetron, given that its operating points are not disturbed. 


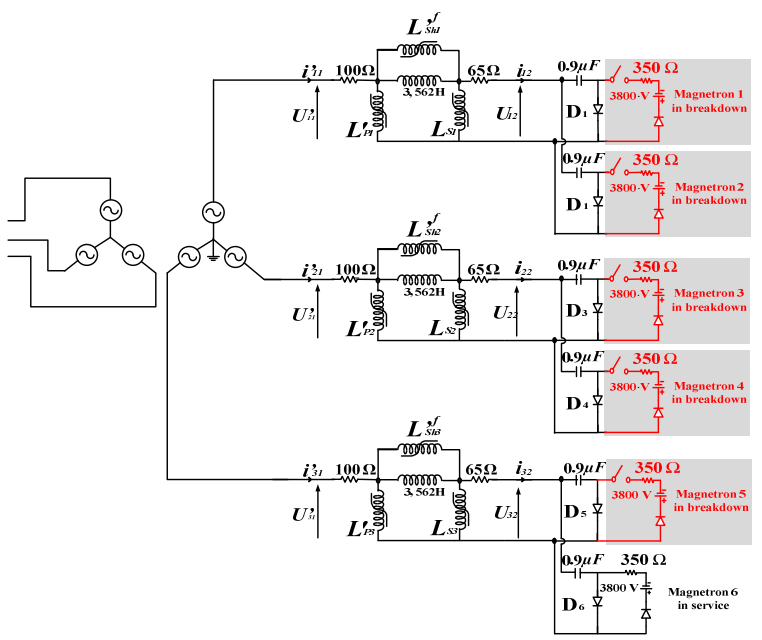

a.
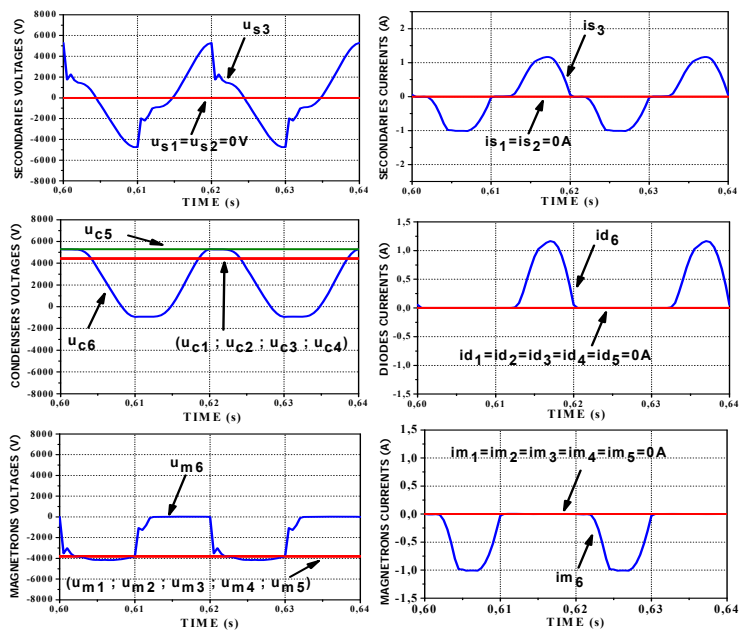

b.

Figure 15. Circuit model: Case of five faulty magnetrons and one magnetron in service, a). Circuit model of a character three phase HV power supply for $\mathrm{N}=2$ magnetrons per phase. Case of five faulty magnetrons, $b$ ).

Waveforms of currents and voltages of the circuit in Figure 15.a.

\subsection{Case of two faulty magnetrons per phase (or six faulty magnetrons)}

All magnetrons are defectives; the microwave generator's system does no longer fulfill its function. It is necessary to change the six faulty magnetrons by new ones; each magnetron has a useful power of 800 watts at $2.45 \mathrm{GHz}$.

\section{CONCLUSION}

We have described in this article a study of the nominal operation's feasibility using EMTP of a new character three-phase high voltage power supply for microwave generators with two magnetrons 800 Watts per phase which can deliver up to 4800 Watts useful power at $2450 \mathrm{MHz}$. Then a study on fault diagnosis magnetrons was also envisaged. The simulation with the EMTP code of the new power supply with two magnetrons per phase allowed us to verify the current control process in each magnetron; which ensures the protection of all magnetrons against any possible variation in voltage entrance of the three-phase supply network. The feasibility test of the electrical operating under nominal conditions of the new three-phase character power supply system with two magnetrons per phase has been proved conclusive. It can be extended without any problem in the case of a power supply with $\mathrm{N}=10$ magnetrons per phase at nominal conditions. On the other hand, the failure of $\mathrm{M}$ among the $\mathrm{N}$ powered magnetrons does not change the functioning of the $(\mathrm{N}-\mathrm{M})$ remaining functional magnetrons $(\mathrm{M}<=\mathrm{N})$. By replacing the faulty magnetron by a functional one (or by a new one), this power supply for six magnetrons (with five magnetrons in service and one faulty magnetron) has similar electrical functioning to that with six functional magnetrons. The study of feasibility of the new three-phase power supply with multi magnetrons per phase (2 magnetrons per phase in our case), led us to initiate the study of the real three-phase power supply with multi magnetrons per phase by modeling and dimensioning adequately its new own correspondent three-phase shunts transformer, which reduces the size, volume, weight and electrical wiring then reduce the cost of implementation and maintenance of microwaves generators.

\section{REFERENCES}

[1] Chraygane M., "Modélisation avec EMTP d'une nouvelle génération d'alimentation haute tension monophasée pour générateurs microondes à magnétrons destinés aux applications industrielles," Thèse de doctorat d'état, Université Ibn Zohr Agadir, Maroc, vol/issue: 113(07), 2007.

[2] M. Ferfra, et al., "Non linear modelling of an overall new high voltage power supply for $\mathrm{N}=2$ magnetrons for industrial microwave generators," J. of PCN, vol. 54, pp. 17-30, 2010.

[3] A. Belhaiba, et al., "Improved optimization of the nominal functioning of a high voltage power supply $\mathrm{n}=2$ magnetrons for microwaves generator," International Journal Of Electrical And Computer Engineering (IJECE), vol/issue: 2(5), pp. 708-716, 2012. 
[4] Teissier M., et al., "Leakage Flux Transformer Modelling," Communication, International Conference on Electric Machines, ICEM’94, Paris, 1994.

[5] M. Chraygane, et al., "Vérification expérimentale de la loi de conservation des flux du transformateur à shunts d'une alimentation pour générateurs micro-ondes à magnétron destinés aux applications industrielles," RNJCP4Casablanca. Comm., pp. 6-7, 2003.

[6] M. Chraygane, et al., "Modélisation d'une alimentation haute tension pour générateurs micro-ondes industriels à magnétron," Revue 3EI, vol. 41, pp. 37-47, 2005.

[7] H. W. Dommel, "ElectroMagnetic Transcients Program,” Reference Manual, EMTP Theory Book, 1986.

[8] V. Dommelen D., "ATP General Introduction," Leuven EMTP Summer Course, 1991.

[9] W. S. Meyer and T. H Liu, “Alternative Transients Program (ATP), Rule Book, Canadian/american,” EMTP User group, pp. 92, 1987.

[10] O. Ahmedou M., et al., "Improved $\pi$ Model of the Leakage Flux Transformer Used for Magnetrons," International Conference on Multimedia Computing and Systems, IEEE Conference, Ouarzazat-Morocco, 07-09 April 2011.

[11] Aguili T. and Chraygane M., "Une alimentation originale pour générateurs micro-ondes," Revue Générale de l'Electricité RGE. France, vol. 5, pp. 49-51, 1990.

[12] M. O. Ahmedou, et al., "New $\pi$ Model Validation Approch to the Leakege Flux transformer of a High Voltage Power Supply Used for Magnetron for The Industrial Microwaves Generators 800 Watts-2450 Mhz," International Review of Electrical Engineering (IREE), vol/issue: 5(3), 2010.

[13] F. de León, et al., "Comparing the T and $\pi$ equivalent circuits for the calculation of transformer inrush currents," IEEE Trans. Power Del, vol/issue: 27(4), pp. 2390-2398, 2012.

[14] S. Jazebi, et al., "A Comparative Study on $\pi$ and $T$ Equivalent Models for the Analysis of Transformer Ferroresonance," IEEE Trans. Power Del, vol/issue: 28(1), pp. 526-258, 2013.

[15] Chan J. H., et al, "Non linear transformer model for circuit simulation," IEEE Transactionson Computer-Aided, vol. 4, pp. 10, 1991.

[16] H. W. Dommel, "Transformer models in the simulation of electromagnetic transients," Fifth Power Systems Computation Conference, England. Comm., 1975.

[17] N. E. Ghazal, et al., "New simulation method of new hv power supply for industrial microwave generators with n=2 magnetrons," International Journal Of Advanced Computer Science And Applications, vol/issue: 4(12), 2013.

[18] A. Bouzit, et al., "Modeling of New Single-Phase High Voltage Power Supply for Industrial Microwave Generators for N=2 Magnetrons," International Journal of Electrical and Computer Engineering (IJECE), vol/issue: 4(2), pp. 223 230, 2014.

[19] M. Chraygane, et al., "Modélisation d'une nouvelle alimentation HT monophasée pour générateurs micro-ondes industriels à N=2 magnétrons," Télécom'2007 et 5ème JFMMA-Fès. Comm., pp. 420-424, 2007.

\section{BIOGRAPHIES OF AUTHORS}

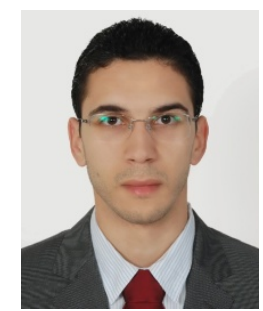

Redouane BATIT was born in Agadir Morocco in 1986; he received his Engineering degree in Industrial Engineering in 2011 from the National School of Applied Science (Ibn Zohr University) Agadir-Morocco, where he pursues his doctoral program. His research is interested in the "Modelling with EMTP of a new three-phase high voltage power supply for industrial microwave generators with $\mathrm{N}=2$ magnetrons per phase"

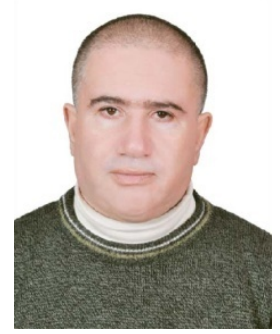

Mohammed CHRAYGANE was born in Morocco in 1963, he received his thesis of doctorat fromClaude Bernard University Lyon I in 1993 and his 'doctorat d'état' from Ibn Zohr University Agadir-Morocco in 2007. In 1994, he joined Technology Higher School Ibn Zohr UniversityAgadir Morocco (ESTA). Since this date he has been a professor in MSTI Laboratory (ESTA) School Ibn Zohr University Agadir Morocco Agadir). His field of interest is modeling a highvoltage power supply used for industrial microwaves generators with magnetron. 